\title{
STUDIES IN OCCUPATIONAL MORBIDITY (1)
}

BY

\author{
W. T. RUSSELL, G. P. B. WHITWELL, AND JOHN A. RYLE \\ From the Department of Social Medicine, Oxford
}

(RECEIVED FOR PUBLICATION, AUGUST 2, 1946)

The influence of occupation on health has been recognized throughout the centuries. More than two hundred years ago Ramazzini, the father of industrial medicine, advised that in the examination of a patient it was of the utmost importance to ascertain the nature of his work. It is clear from his descriptions that he made himself intimately acquainted with the working conditions obtaining in a wide variety of employments. To-day it is recognized that an efficient industrial medical officer, in order to complete his contributions to the prevention and treatment of sickness and injury and to factory hygiene, should, ideally, acquaint himself with the precise nature of every occupation upon which members of his working population may be engaged, and as far as possible with the previous health and occupational histories of all employees brought under his observation.

Although an increasing interest has been taken since Ramazzini's time in the possible correlations between occupation and sickness, accurate information remained for a long time fragmentary. It was not until Farr initiated in this country the collection of figures bearing on occupational mortality that any degree of precision in our knowledge was attained. His researches in this field, like his other investigations, have been regarded as classic studies, and the policy which he originally formulated governed the compilation of data up to 1920 . In the Occupational Mortality Supplement of the Registrar-General for 1921-3, an attempt was made to collect the statistics on an occupational rather than, as previously, a purely industrial basis. The differentiation is important because under the industrial allocation the mortality of some trades was heavily diluted by the inclusion of figures for other workers industrially related but not exposed to the same occupational risk. This was particularly true of workers engaged in occupations involving risk of silicosis. This alteration was, then, the first improvement in our more precise knowledge of occupational influence.
In the succeeding Supplement, based on the statistics for the years 1930-2, a still more important addition was made, for not only was the mortality of the male workers recorded, but also that of the wives of workers engaged in corresponding occupations. This information enabled a comparison to be made between direct and indirect occupational influence, because, if the excess mortality in an occupation was observable amongst males only, then the implication would be that the cause was purely occupational. If, on the other hand, both men and women experienced abnormal rates of mortality, then the high incidence could more legitimately be ascribed to the effects of a bad social environment. This idea of comparing the mortality of men and wives was not a new conception. Hay, who was interested in the relative influence of ' seed and soil' in tuberculosis, analysed similar statistics in Aberdeen many years ago. Nevertheless, the Registrar-General has considerably enriched our knowledge of medical statistics by his publication of the national data. From the information which he has compiled in this extremely valuable report, we learn that the seven occupations with the highest standardized mortality ratios (registered deaths expressed as a percentage of the calculated or expected number of deaths in the particular occupation) amongst males aged 20-65 were:

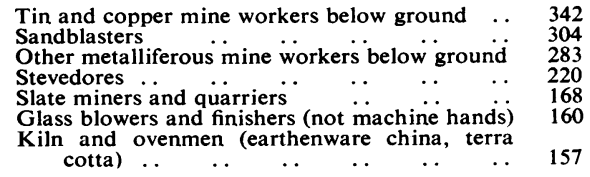

In this list, six out of the seven specified occupations indicate the risks from silicosis, and in the remaining one the causal factor is probably a generally unsatisfactory environment.

We also find that there are instances in which married women have a mortality in excess of the average for all wives, but in which that of the males 
in the corresponding occupation is a normal experience. This phenomenon is strikingly emphasized in the cotton industry, especially amongst textile spinners, the figures for men and wives being 105 and 124 respectively. The wives, or some of them, work in the mills and have the additional burdens of domestic responsibility.

The knowledge which we have gleaned from occupational mortality data is, on the whole, very instructive; but it does, nevertheless, lack precision for the following reason: the occupation entered on the death certificate is that at which the deceased worked prior to his death, but during his working life the man may have changed his trade or occupation several times, with the result that the one ascribed at death may be of an entirely different character from that which initially influenced his health. For this reason a study of occupational morbidity is much preferable to that of occupational mortality. In the main this has hitherto been a relatively unexplored field. Our knowledge has been chiefly derived from the admirable ad hoc investigations made by the scientific staff of the Industrial Health Research Board and available in the Board's publications, and also from the Annual Reports of H.M. Inspector of Factories.

Industrial managements in the past, with a few exceptions, have never been particularly interested in the sickness absence of their employees, despite the fact that the time lost and the sickness claims on benefit societies were of considerable magnitude, being in average pre-war years of the order of $26,000,000$ working weeks with a sickness payment of something like $£ 18,000,000$.

It may be said that the impact of two wars, and the necessity of maintaining a high standard of output under the prevailing difficulties of transport and blackout conditions at work, made the supervision of the health of the workers a primary national consideration. Furthermore, the introduction of new types of industry arising out of war-time research, especially the manufacture of radioactive luminous paints, accentuates the importance of studying the health of those engaged in such processes. The introduction of new hazards in connexion with work arising out of atomic research will shortly necessitate the most watchful study of health and sickness in all persons at risk in Government or other laboratories and research centres and in related industries. It must be hoped that the health studies inaugurated during the initial war years will become a permanent policy of the industrial world generally. Certainly some of the more progressive industrial managements are alive to this necessity, and evidence of their interest is reflected in the extension and improvement of their sickness records, by which we have ourselves been greatly assisted in our preliminary studies in the area under review. The sickness absence form suggested by the Industrial Health Research Board (Report No. 85) has, in our experience in the factories under review during the past year, improved the value of records very considerably and rendered them more suitable for statistical analysis than those previously in use.

\section{Data of Present Investigation}

The present investigation, which is to be regarded as a pilot study, is based on the sickness recorded in a particular organization during 1944, in which 2,681 males and 7.17 females were engaged in either production or non-production work, and for whom relevant particulars of age were recorded. The population was composed of $(a)$ workers present during the whole year, $(b)$ leavers. There were no entrants. The leavers were regarded as being exposed to risk on the average for half a year, since the exact date of leaving was not recorded. Thus each leaver contributed half a unit to the yearly population. We say "pilot study" advisedly, because there were defects inherent in the data-such as a considerable amount of uncertified sickness, the nature of which was not specified. Even as regards certified illness there were imperfections in the records, because in many instances the specific cause of sickness on the medical certificate could not be deciphered by the Welfare Department and as a consequence the man's record card was merely marked with a ' $\mathrm{C}$ ' to indicate that he had a certificated absence. Accordingly in the present analysis certified illness was grouped under two headings: (1) certified and classified-i.e., the specific cause was known; (2) certified and unclassified-which represented men and women whose record card was merely marked ' $C$.' It must also be accepted that at the present time doctor's certificates allow only rough classification into main categories of illness. It is to be hoped that difficulties of this kind will in time be remedied in the interests alike of medical science, the worker, and the employer. The correct assessment of sickness and its causes, in so far as they may be related to working conditions, must depend very largely on improved certification and classification.

\section{Production and Non-Production Groups-General Description}

The two main groups of factory work can be roughly divided into 'non-production' and 'production.' Staff and clerical categories must not be forgotten, but are not here considered. The production group were the 
assemblers, fitters, welders, labourers, and inspectors. The non-production or auxiliary services included the police, fire brigade, cleansing department, transport, and electrical and machine maintenance. In this non-production group are included the elderly or unfit. Nevertheless in non-production work there are also adverse health factors. Among these should be mentioned changes of shift, necessity for working at week-ends, and, in some cases, long hours. Some factory maintenance has to be done at week-ends when the production side is idle. Working at these irregular hours involves missing the advantages of convenient works buses and trains. This of necessity adds to fatigue.

The production side, on the whole, have worked reasonable hours (about 48 per week) in the period covered. They did but little shift work. The work was often interesting and well paid.

\section{Uncertified Sickness}

The large amount of uncertified sickness is a feature of some importance. The labour management accept as a rule the word of a man when he states that his absence has been due to sickness. The reason for this is that the factory often retains its employees for long periods of their working lives. The management, because of this, are perfectly familiar with the good faith of their employees. This attitude, benign though it be, must be regarded as a serious obstacle to the detailed investigation of sickness absence.

\section{Standardizing Sickness Rates for Age}

Since sickness rates are generally a function of agethey increase with increasing age of the workers-it is necessary, when instituting comparisons between the total sickness rate in one organization with that in another or within the different departments of the same organization, or in comparing the total morbidity rate of males and females, to eliminate the influence of the age factor, or, as it is commonly called, to 'standardize for age.' The process of doing so is now generally familiar to students of public health and is described in all textbooks on vital statistics. In the present instance the population used as a 'standard' was the total working population of the factory in question, distributed in the following age groups:

Age group
$14-20$
$21-25$
$26-35$
$36-45$
$46-55$
$56-60$
61 plus

\begin{tabular}{c} 
Persons \\
210 \\
215 \\
654 \\
1,103 \\
843 \\
196 \\
177 \\
\hline 3,398 \\
\hline
\end{tabular}

It will be noted that the age grouping is slightly dissimilar to that used by the Registrar-General-i.e. 21-25 years instead of 20-24 years. The difference was due to a misinterpretation, but in future work the RegistrarGeneral's age grouping will be adopted.

Percentage of Workers Absent

The percentage of employees absent through illness is stated with standard errors in Table 1.
TABLE 1

NUMBER OF WORKERS PER 100 TOTAL EMPLOYEES ABSENT THROUGH VARIOUS CAUSES

\begin{tabular}{|c|c|c|c|c|c|c|c|c|}
\hline \multirow{3}{*}{ Sickness } & \multicolumn{4}{|c|}{ Production } & \multicolumn{4}{|c|}{ Non-production } \\
\hline & \multicolumn{2}{|c|}{ Males } & \multicolumn{2}{|c|}{ Females } & \multicolumn{2}{|c|}{ Males } & \multicolumn{2}{|c|}{ Females } \\
\hline & $\%$ & S.E. & $\%$ & S.E. & $\%$ & S.E. & $\%$ & S.E. \\
\hline $\begin{array}{ll}\begin{array}{c}\text { Certified } \\
\text { classified }\end{array} & \text { and } \\
\begin{array}{c}\text { Certified but un- } \\
\text { classified }\end{array} & \ldots \\
\begin{array}{l}\text { Uncertified } \\
\text { No illness }\end{array} & \ldots \\
\text { No }\end{array}$ & $\begin{array}{l}22 \cdot 3 \\
18 \cdot 9 \\
55 \cdot 6 \\
25 \cdot 1\end{array}$ & $\begin{array}{l} \pm 1 \cdot 16 \\
\pm 1 \cdot 09 \\
\pm 1 \cdot 38 \\
\pm 1 \cdot 21\end{array}$ & \begin{tabular}{|l|}
$19 \cdot 3$ \\
$32 \cdot 9$ \\
$80 \cdot 8$ \\
$16 \cdot 0$
\end{tabular} & $\begin{array}{l} \pm \mathbf{2 \cdot 2 8} \\
\pm \mathbf{2 \cdot 7 1} \\
\pm \mathbf{2 \cdot 2 7} \\
\pm \mathbf{2 \cdot 1 2}\end{array}$ & $\left|\begin{array}{l}23 \cdot 7 \\
24 \cdot 3 \\
54 \cdot 1 \\
27 \cdot 4\end{array}\right|$ & $\begin{array}{l} \pm 1 \cdot 14 \\
\pm 1 \cdot 15 \\
\pm 1 \cdot 34 \\
\pm 1 \cdot 20\end{array}$ & $\left|\begin{array}{l}23 \cdot 4 \\
20 \cdot 5 \\
75 \cdot 2 \\
25 \cdot 1\end{array}\right|$ & $\begin{array}{l} \pm 2 \cdot 07 \\
\pm 1 \cdot 98 \\
\pm 2 \cdot 12 \\
\pm 2 \cdot 12\end{array}$ \\
\hline Population & & 291 & & 300 & & 1,390 & & 417 \\
\hline
\end{tabular}

Rates standardized for age.

The ratios for each category of illness are not additive, because in many instances employees had both an uncertified illness and a certified illness during the year; hence they are included in both categories. Thus, although the percentages represent the actual incidence for each type of sickness category, their summation would overstate the proportion of workers who had been ill during the year. As has been indicated, the percentage of workers who had uncertified illness is high. For males, the proportion was 55 per cent., with little divergence between the production and non-production departments. In this respect the statistical experience of females was much worse than that of males, as their absenteeism from this cause was as high as 80.8 per cent. in the production departments. There was little sex difference for specific causes of certified illness, the percentage for both sexes being of the order of 20 per cent., and, with the exception of females engaged in the production departments, the

TABLE 2

NUMBER OF OCCURRENCES OF ILLNESS PER 100 TOTAL EMPLOYEES DURING 1944 IN AGGREGATED PRODUC TION AND NON-PRODUCTION DEPARTMENTS.

\begin{tabular}{|c|c|c|c|c|}
\hline \multirow{2}{*}{ Sickness } & \multicolumn{2}{|c|}{ Production } & \multicolumn{2}{|c|}{ Non-production } \\
\hline & $\underset{\%}{\text { Males }}$ & $\underset{\%}{\text { Females }}$ & $\underset{\%}{\text { Males }}$ & $\underset{\%}{\text { Females }}$ \\
\hline $\begin{array}{cc}\text { Certified } & \text { and } \\
\text { classified } & \ldots \\
\text { Certified but } & \text { un- } \\
\text { classified } & \ldots\end{array}$ & $26 \cdot 6$ & $48 \cdot 4$ & $34 \cdot 5$ & $24 \cdot 6$ \\
\hline Total & $54 \cdot 6$ & $71 \cdot 3$ & $59 \cdot 3$ & $48 \cdot 8$ \\
\hline
\end{tabular}

Rates standardized for age. 
proportion of the workers who had not been absent on account of illness during the year was of the order of 25 per cent.

Percentage of Occurrences of Certified Sickness.The relevant statistics are stated in Table 2. The proportion of occurrences amongst males was fairly constant, being 54.6 per cent. in the production departments as compared with $59 \cdot 3$ per cent. in the non-production, but there was appreciable variation for females, the comparable rates being 71.3 per cent. and 48.8 per cent. The high incidence among the women engaged on production was due to unclassified sickness for which they produced a certificate. The slightly higher male figures for certified sickness in the non-production as compared with production groups probably reflects the employment here of men rendered unfit for more arduous occupations by disabilities in the 'chronic' category, etc.

Percentage Time Lost (Certified and Uncertified).The percentage of possible working time lost on account of illness amongst employees engaged on production and non-production work is stated in Table 3 . There was slightly more time lost in the production departments, the rates being 4.01 per

$$
\text { TABLE } 3
$$

PERCENTAGE OF POSSIBLE WORKING TIME LOST DURING 1944 FROM ILLNESS IN AGGREGATED PRODUCTION AND NON-PRODUCTION DEPARTMENTS

\begin{tabular}{|c|c|c|c|c|}
\hline \multirow{2}{*}{ Sickness } & \multicolumn{2}{|c|}{ Production } & \multicolumn{2}{|c|}{ Non-production } \\
\hline & Males & Females & Males & Females \\
\hline $\begin{array}{l}\text { Certified illness } \\
\text { Uncertified }\end{array}$ & $\begin{array}{l}3 \cdot 12 \\
0 \cdot 89\end{array}$ & $\begin{array}{l}2 \cdot 61 \\
1 \cdot 19\end{array}$ & $\begin{array}{l}2.97 \\
0.89\end{array}$ & $\begin{array}{l}2 \cdot 39 \\
1 \cdot 18\end{array}$ \\
\hline Total & $4 \cdot 01$ & $3 \cdot 80$ & $3 \cdot 86$ & $3 \cdot 57$ \\
\hline
\end{tabular}

Rates standardized for age.

cent. for males and 3.80 per cent. for females, as compared with 3.86 per cent. and 3.57 per cent., but the differences are unimportant. On both types of labour the aggregate rate for females was lower than that for males, but this result was entirely due to their lower incidence of certified illness because, in point of fact, their lost time from uncertified illness was relatively greater than that for males.

Time Lost per Employee (Certified and Uncertified).-Another method of illustrating the effect of sickness on output is to express the days absent in terms of the working population and obtain the average time lost per employee. The necessary calculations were made and are shown in Table 4. It will be noted that both in production and nonproduction work, irrespective of type of sickness,
TABLE 4 AVERAGE NUMBER OF WORKING DAYS LOST BY SICK-
NESS PER EMPLOYEE DURING 1944 IN AGGREGATED PRODUCTION AND NON-PRODUCTION

\begin{tabular}{cc|c|c|c|c}
\hline \multirow{2}{*}{ Sickness } & & \multicolumn{2}{c|}{ Production } & \multicolumn{2}{c}{ Non-production } \\
\cline { 3 - 5 } & & Males & Females & Males & Females \\
& & & & & \\
\cline { 3 - 5 } & & days & days & days & days \\
Certified &. & 9.37 & 7.45 & 8.93 & 7.20 \\
Uncertified &. & 2.69 & 3.54 & 2.68 & 3.55 \\
\hline \multicolumn{1}{c|}{ Total } &. & 12.06 & 10.99 & 11.61 & 10.75 \\
& & & & & \\
\hline
\end{tabular}

Rates standardized for age.

the women lost less time than the men. The average loss by men was 12.06 and 11.61 days respectively, the comparable values for females being 10.99 and 10.75 days. The lower averages for women were entirely due to their more favourable experience from certified illness, because from uncertified causes their loss was almost one day in excess of the average for men.

Average Duration of Certified Illness.-Although the time lost per female employee from certified illness was lower than that for the male, the occurrence of this sickness (as shown previously-Table 2) was relatively more frequent among women than among men in the production, and not very different in the non-production departments. Such facts would imply that, in the production departments at least, there existed an appreciable sex difference in the average duration of certified illness. The relevant statistics are recorded in Table 5, in which

TABLE 5

AVERAGE DURATION IN DAYS OF CERTIFIED SICKNESS DURING 1944

\begin{tabular}{|c|c|c|c|}
\hline \multicolumn{2}{|l|}{ Department } & Males & Females \\
\hline Production $\quad \ldots$ & . & $17 \cdot 16$ days & 10.45 days \\
\hline Non-production & .. & 15.06 days & $14 \cdot 75$ days \\
\hline
\end{tabular}

Rates standardized for age.

it will be observed that the only divergence between averages for males and females existed in the production shops, in which the average duration of female illness was nearly 7 days shorter than that for men.

\section{Sickness-Proneness}

Since it was possible to obtain the number of certificates granted to each worker on account of sickness absence, a frequency distribution was made 
for males and females who had been employed for the complete year. Leavers were thus excluded. The results are given in Table 6 . It will be noticed

TABLE 6

FREQUENCY DISTRIBUTION OF EMPLOYEES ACCORDING TO NUMBER OF SICKNESS CERTIFICATES GRANTED DURING 1944

\begin{tabular}{|c|c|c|c|c|}
\hline \multirow{2}{*}{$\begin{array}{l}\text { No. of cert- } \\
\text { ificates }\end{array}$} & \multicolumn{2}{|c|}{ Males (all ages) } & \multicolumn{2}{|c|}{ Females (all ages) } \\
\hline & $\begin{array}{c}\text { Actual } \\
\text { number }\end{array}$ & $\begin{array}{l}\text { Expected } \\
\text { number }\end{array}$ & $\underset{\text { number }}{\text { Actual }}$ & $\begin{array}{c}\text { Expected } \\
\text { number }\end{array}$ \\
\hline \multirow[t]{2}{*}{$\begin{array}{l}0 \\
1 \\
2 \\
3 \\
4 \\
5 \\
6 \\
7\end{array}$} & $\begin{array}{r}1,656 \\
588 \\
203 \\
57 \\
17 \\
8 \\
1\end{array}$ & $\left.\begin{array}{r}1,652.07 \\
598 \cdot 65 \\
193.40 \\
59.95 \\
18 \cdot 19 \\
5.45 \\
1.62 \\
0.48\end{array}\right\} 7 \cdot 55$ & $\begin{array}{r}359 \\
136 \\
43 \\
11 \\
3 \\
- \\
-\end{array}$ & $\left.\begin{array}{r}356.68 \\
141.11 \\
40.76 \\
10.32 \\
2.43 \\
0.55 \\
0.12\end{array}\right\} 13.42$ \\
\hline & 2,530 & $2,529 \cdot 81$ & 552 & 551.97 \\
\hline & $\begin{array}{l}=1 \cdot 107 \\
=3 \\
>P>0\end{array}$ & & $\begin{array}{l}=0.362 \\
=1 \\
7>P>0\end{array}$ & \\
\hline
\end{tabular}

that the distribution in each instance is of a skew character. Of the 2,530 males, 1,656 had no certified illness and 9 workers had as many as five or more illnesses each during the year. For females the number who did not have a certified illness totalled 359, and 3 women were ill on four occasions. Assuming that all the workers were equally likely to contract an illness requiring a certificate, a theoretical distribution was evaluated on the basis that the data were in accord with a Poisson series. The resultant values of this theoretical distribution did not justify the hypothesis of equal liability. Next, it was assumed that some workers were more liable than others to contract illness or to ' go sick'; that there may, in fact, exist a ' sickness-proneness' as well as the generally recognized ' accident-proneness .' To test the validity of this assumption a negative binomial curve was fitted to the data, and the expected distributions for males and females arising from this hypothesis are stated in the third and fifth columns of table 6. It will be seen that there is a very close correspondence between the fact and the theory. For males the value of $\chi^{2}$ is $1 \cdot 107$ and for $\mathbf{N}=3, P$ lies between 0.8 and 0.7 which indicates that, on the basis of our hypothesis of unequal liability, differences as great or greater than those now observed between the actual and predicted values would arise in at least 70 per cent. of trials by mere chance. For females the concordance was equally satisfactory, the value of $\chi^{2}$ being 0.362 and for $N=1 P$ lies between 0.7 and 0.5 .

Such 'sickness-proneness' might be due, on the one hand, to a too-ready ' habit of going sick' in the absence of demonstrable disease, or, on the other, to chronic illness with exacerbations necessitating frequent absences. It is clearly important to separate these causes. Bashford (1942), although not under this heading, discusses cases of what might well be called 'sickness-proneness' in post-office employees:

' Over and over again he (the medical officer) will find some such factor as groundless anxiety, thwarted or seemingly thwarted ambition, some personal antagonism, real or fancied, to a particular job or fellowworker or foreman or office superior; and he will be able to make an adjustment which results in an immediate and permanent alteration in the sick record. Or he may find some factor of irresponsibility, not of malingering in any serious sense, but of a too lighthearted taking of a day or two off for medical or semimedical reasons. Few people, and especially young people, memorize their own sick records; and many when confronted with them in black and white are genuinely surprised by their extent; often a complete alteration is the result. If there is no change and no definite physical or psychological cause is discovered for repeated minor sick absences, a kindly intimation that if the record continues as in the past the question of retirement or discharge on medical grounds will arise may have a considerable effect. This was illustrated in a group of workers on whom I have previously reported. Over about four years this group of 40 people, mostly young, had incurred between them 736 separate sick absences, totalling 6,194 days; after receiving the intimation described, these 40 people during the next 6 months only incurred 54 days' sick absence, their 6-monthly average of illness dropping from 19 days a head to $1 \cdot 3$. It would be unfair to describe supervision of this sort as medical police-work in any vindictive sense, since it was clearly of benefit not only to the departments but to the workers concerned; and it may be that such supervision may prevent the development in later years of a valetudinarian outlook on life much harder to combat. In any large staff there will also probably be cases in which the real reason for continued minor illnesses is a fundamental dislike to the particular occupation. In such cases, medical advice to seek some other mode of life is probably in the truest interest of the employee.'

The records of the 8 cases among male workers with five instances of certified illness in the year, 1 male worker with seven instances, and the 3 female cases with four instances of certified illness in the year were studied in closer detail with the following results.

Of the males, 7 were in the chronic illness group, but 2 suffered from that factor of social irresponsibility to which Bashford drew attention. Among the 7 chronic illnesses there were 2 cases of pulmonary tuberculosis, 1 of chronic nephritis, 1 of old age and bronchitis, 1 of chronic bronchitis and asthma, and 2 of psychoneurosis.

One of the psychoneurotics had claustrophobic symptoms since being subjected to 17 hours' continuous divebombing. His symptoms improved when he was in the open air. Many psychoneurotics are at their best in open-air work. 
The two cases of social irresponsibility form a special group. One of them, owing to unstated cause of absence, was interviewed by the labour manager. He gave as a reason 'rheumatism in the neck,' although the foreman saw nothing wrong in the manner in which he was doing his work. He accepted an appointment for treatment for which he never turned up. Almost immediately, he had eight weeks off work with ' gastric catarrh.' On return to work he stated that the symptoms of this had been present for six years and consisted of swimming in the head, poor appetite, and epigastric pain unrelated to food. He had never had hospital investigation for these symptoms. He was again interviewed after a further absence from work. This time the symptoms were given as 'melancholy agitation with irritability.' He then worked at a neighbouring factory where he had a long spell away because his wife had left him. He was a prominent and regular member of a dance band.

The other case had a variety of diagnoses on his medical certificates. On one occasion he refused work because of lumbago. This was accepted, even though he also had no desire for treatment to enable him to do his work. He neglected to use protective equipment and developed ' arc eyes' due to welding. When he subsequently had dyspepsia, he attributed this to having to wear protective equipment.

The above two cases would not be re-engaged by the labour manager on any conditions. Nevertheess, it is only fair to state that the industrial efficiency of this type must depend to some extent on the quality of the foremanship in the factory, and there is evidence that the second case developed a grudge against the firm, having previously been a satisfactory employee for many years.

Of the 3 females with multiple absences there was 1 case of recurrent bronchitis, 1 of recurrent fibrositis, and 1 case of social irresponsibility.

This last case was that of a single girl in billets with no arduous duties. She lost time with recurrent dyspepsia and a severe cold. She appeared to be apathetic, but in the best of health. Her long-standing dyspepsia had never had hospital investigation, neither did she desire it. Her absences were so suspicious that she came before the absentee tribunal. She was discharged from the firm and would at no time be re-engaged.

Among the 12 cases considered under this heading, there were thus 3 cases of 'social irresponsibility' -2 male and 1 female. The remainder had chronic or recurring physical disabilities. We have, unfortunately, no means of ascertaining what proportion of the cases of recurrent uncertified sickness should be attributed to 'social irresponsibility' or to a too ready utilization of minor symptoms or maladjustments to the working environment.

In further communications it is hoped to take up such questions as the incidence of main types of illness occasioning absence in the same factory, and, so far as possible, to correlate these with age, sex, length of employment, trade, season, etc.

\section{Summary and Conclusions}

The investigation was based on the absenteeism due to sickness amongst 2,681 males and 717 females engaged in the production or non-production departments of a particular industrial organization during the year 1944 . The main conclusions are:

1. Although the occurrence of certified illness was relatively more frequent amongst women than amongst men in the production departments, its average duration was approximately 7 days shorter.

2. The percentage of possible time lost on account of certified sickness was lower for women than for men in both the production and non-production shops, but their rates for uncertified illness were greater.

3. There is evidence to indicate, both amongst men and women, that in the case of certified illness there were some workers who had a 'sickness-proneness' due either to chronic or recurring physical disabilities, or to social irresponsibility. It is reasonable to suppose that 'sickness-proneness' will also occur in the uncertified group.

4. The rates of uncertified illness in the industry under review are high and suggest the need for a reconsideration of policy in respect of certification requirements. This would be in the interests alike of the worker, the employer, and of future investigations of occupational morbidity and its causes.

5. The sickness absence form (Report No. 85) devised by the Industrial Health Research Board has greatly improved the value of the records now being put at our disposal for future use, as it has helped to avoid some of the defects inherent in the data on which the present analysis was based.

\section{REFERENCES}

Bashford, H. (1942). Lancet, 2, 289.

Hay, M. (1909). Ann. Rep. Med. Off. Hlth., Aberdeen.

Registrar-General (1931). Decennial Supplement. England and Wales. Part IIa. Occupational Mortality. 